\title{
Year of Expectation
}

\section{EI)IT()RIAL,}

There are several things which make this year one of expectation of significant advances in knowledge in the leprosy field. The Seventh International Congress of Leprology is to be held in New Delhi from 8th to 16 th November, I958. Such international leprosy congresses are held only at intervals of five years; each previous one. seen retrospectively, was undoubtedly a giant's stride forward, and it is reasonable to expect the Delhi one will be no exception.

One of the most fascinating subjects will certainly be the reports on the wide scale campaigns to control leprosy in countries of high endemic prevalence. Since DDS was brought into wide use about I949 or I950 there has been a strong tendency to use this therapy as a means of control, perhaps even the main means of control. Does it work? It is hoped that many reports will come in, so this matter can be assessed. Already there is evidence that it does work, for the Nigerian campaign has shown that one can imbed a large component of mass treatment in the leprosy control scheme, and get remarkable results in the reduction of leprosy prevalence which have every appearance of being permanent.(1)

Another question about which expectation will gather is the use of BCG as a prophylactic against leprosy. Time is needed to prove that it does protect, and the five years since the last congress should have produced more evidence. Some countries have already used BCG on a large scale, and reports from them will be of the greatest interest. Controlled experiments have also been in progress.

There is also great interest and expectation in the possibility of new drugs becoming available for the treatment of leprosy. Since Davey (2) and others made their report on a three year trial of a diphenylthiourea compound called DPT, and indicated its freedom from toxicity allied to a certain calm efficiency, the results of trials in many parts of the world will be awaited eagerly, and some of them may mature in time for the Delhi Congress. Fuller information on the pharmacology and biochemistry of DPT may also then be available. Other drugs which may be said to loom over the horizon are the surface-active agents and the ethyl thiolesters. The surface-active agents (polyoxyethylene ethers) are represented by Triton WR I339 and Macrocyclon, and Rees ${ }^{(3)}$ has reported favourable results against murine leprosy with twice-weekly subcutaneous injections of them, and a trial elsewhere in human leprosy is in progress. The ethyl thiolesters, in particular diethyl dithiolisophthalate, have been studied by Davies and Driver, (4) and have a marked action on experimental tuberculosis by injection and even by inunction; they have a marked effect in weekly doses and combined treatment with INH proved much better than either the 
ethyl thiolester or INH alone, and there is no cross-resistance. A trial in human leprosy in due course seems indicated.

There is also reasonable expectation of developments in culture in vitro of $M$. leprae murium, which eventually may make possible the culture of the human leprosy bacillus. Rees and Wong(5) in February 1958 reported limited multiplication of the murine leprosy bacillus in tissue culture. Rees had found that the generation time of $M$. leprae murium, in vivo, was I3 days. $(6,7)$ Based on this, the authors devised a method for counting the total number of bacilli per culture before and after cultivation. In their earlier attempts to culture the bacillus monocytes were used, but even after 80 days no multiplication could be shown, though $W_{\text {ong }}\left({ }^{(8)}\right.$ showed that bacilli recovered from some of these cultures were still infective. When they used tissues obtained from previously infected animals multiplication did occur. They used explanted spleen cells from infected mice and in fivc experiments showed there was a limited multiplication which occurred at the $5^{\text {th }}$ day and which corresponds closely to that observed in vivo. They think that continued multiplication requires a regular supply of healthy cells, preferably in a medium containing a low concentration of serum, and are investigating methods to provide these culture conditions. Hawking, in this issue of Leprosy Review reports on an attempt to grow M. leprae murium in macrophages, following a suggestion of Rees. The macrophages were obtained from the rat peritoneum and the fluid medium contained $40 \%$ serum, and fresh supplies of uninfected macrophages were added every 3 to 4 weeks as required. The bacilli have been maintained in cultures of macrophages for over 6 weeks, and in the most favourable culture the number of bacilli doubled during a period of 52 days. Cultures were still infective to rats after incubation for 42 days.

A method of animal transmission has been tried by Bergel of Argentina ${ }^{(9)}$ who fed rats on a pro-oxidant diet (low in Vitamin E and containing linseed oil) and inoculated them with human leprosy bacilli. There was a control series of inoculated rats kept on a normal diet, wherein there was no evidence of multiplication of the bacilli. The rats on the special diet, however, as well as testicular atrophy and disappearance of body fat, showed at first a phase of granulation and decrease in number of the inoculated bacilli, followed by an increase in number of the bacilli, which became again homogenous, and globi were seen. Material from the first series of rats was used to inoculate a second series, and again a third series from the second series, and multiplication seemed to occur throughout. This work awaits development and confirmation. Similarly K. R. Chatterjee of Calcutta, in a personal communication of roth March, 1958, gives advance information of 
his success in transmitting human leprosy to a species of laboratory bred hybrid black mice, and in establishing the infection in them by successive passages. The transmitted infection seems very heavy in the mice involving almost all tissues, including skin and peripheral nerves.

Other subjects about which it is fair to be expectant in $195^{8}$ are the morphological studies of the human leprosy bacillus by electronmicroscopy, closer histological study of the skin in leprosy and the fine nerves of the skin and the light this may throw on the path of invasion of the leprosy bacillus and the tissue reaction to it, studies of the lepromin test and of immunology, the increasing and beneficial interest of orthopaedic surgeons in the prevention and cure of leprosy deformities, and the growing plans for rehabilitation of leprosy patients when their disease is arrested. There are many others; it should be a good year.

\section{REFERENCES}

1. Editorial, Leprosy Review, 29, No. 1, Jan. 1958, p. 16.

2. Davey, T. F. et al, Leprosy Review, 29, No. 1, Jan. 1958, pp. 25-44.

3. Rfes, R. J. W., Amer. Rev. of Tuberc. and Pulm. Dis. 76, No. 5, Nov. 1957, pp. 915-916.

4. Davifs, G. E. and Driver, G. W., Brit. J. of Pharm. and Chemotherapy, 12, No. 4, Dec. 1957, pp. 434-437.

5. Rers, R. J. W. and Wong, P. C., Nature, London, 1 Feb. 1958, 181, No. 4605, Pp. 359-360.

6. Refs, R. J. W., Amer. Rev. Tuberc. 1956, 76, p. 915.

7. Refs, R. J. W. East Afr. Med. J. 1957, 34, p. 361.

8. Wong, P. C., Ph.D. thesis, London Univ., 1957.

9. Bergel, M., Semana Médica, Sept. 5, 1957, 111 , No. 10, pp. 479-87. 